\title{
Comparison between AMSR-E ASI sea-ice concentration product, MODIS and pseudo-ship observations of the Antarctic sea-ice edge
}

\author{
Xi ZHAO, ${ }^{1}$ Haoyue SU, ${ }^{1}$ Alfred STEIN, ${ }^{2}$ Xiaoping PANG ${ }^{1}$ \\ ${ }^{1}$ Chinese Antarctic Center of Surveying and Mapping, Wuhan University, Wuhan, China \\ E-mail: pxp@whu.edu.cn \\ ${ }^{2}$ Faculty of Geo-Information Science and Earth Observation, Twente University, Twente, The Netherlands
}

\begin{abstract}
The performance of passive microwave sea-ice concentration products in the marginal ice zone and at the ice edge draws much attention in accuracy assessments. In this study, we generated 917 pseudo-ship observations from four Moderate Resolution Imaging Spectroradiometer (MODIS) images based on the Antarctic Sea Ice Processes and Climate (ASPeCt) protocol to assess the quality of the Advanced Microwave Scanning Radiometer for Earth Observing System (AMSR-E) ARTIST (Arctic Radiation and Turbulence Interaction STudy) Sea Ice (ASI) concentrations at the ice edge in Antarctica. The results indicate that the ASI pixels in the pseudo-ASPeCt observations have a mean ice concentration of $13 \%$ and are significantly different from the well-established $15 \%$ threshold. The average distance between the pseudo-ice edge and the $15 \%$ threshold contour is $\sim 10 \mathrm{~km}$. The correlation between the sea-ice concentration (SIC), $\mathrm{SIC}_{\mathrm{ASI}}$ and $\mathrm{SIC}_{\mathrm{MODIs}}$ values at the ice edge was considerably lower than the high coefficients obtained from a transect analysis. Underestimation of $\mathrm{SIC}_{\mathrm{ASI}}$ occurred in summer, whereas no clear bias was observed in winter. The proposed method provides an opportunity to generate a new source of reference data in which the spatial coverage is wider and more flexible than in traditional in situ observations.
\end{abstract}

KEYWORDS: sea ice

\section{INTRODUCTION}

Sea ice is sensitive to temperature changes, and its changing extent serves as an indicator of climate change in polar regions (Massom and Stammerjohn, 2010). Therefore, accurately identifying the location of the ice edge is important for estimating the total ice extent and for determining the overall mass balance of sea-ice coverage (Parkinson and Cavalieri, 2012). From the first satellite microwave radiometers launched in 1972 until now, passive microwave radiometers have provided full coverage of the polar regions. Among them, the Advanced Microwave Scanning Radiometer for Earth Observing System (AMSR-E) has the highest spatial resolution $(6.25 \mathrm{~km})$ and has a wide range of frequencies that provide a more accurate measure of sea-ice extent (Spreen and others 2008).

The publicly distributed standard AMSR-E sea-ice concentration (SIC) products are generated using the ARTIST (Arctic Radiation and Turbulence Interaction STudy) Sea Ice (ASI) algorithm at $6.25 \mathrm{~km}$ resolution and the NASA Team 2 (NT2) algorithm at 12.5 and $25.0 \mathrm{~km}$ resolution. Previous studies have compared SIC retrieval with retrieval from higherresolution optical and synthetic aperture radar (SAR) sensors (e.g. Heinrichs and others, 2006; Lee and Han, 2008), as well as with in situ ship observations (e.g. Worby and Comiso, 2004; Ozsoy-Cicek and others, 2011). These assessments were generally positive and indicated strong agreement of SIC with similar formations of the sea-ice edge among different satellite data (Heinrichs and others, 2006). Cavalieri and others (2006) assessed the performance of AMSR-E NT2 products using Landsat ETM+ and airborne microwave imagery under winter conditions in the Arctic, and found a bias ranging from $0 \%$ to $3 \%$ and a root-mean-square error (RMSE) ranging from $1 \%$ to $7 \%$ for all ice types. On the other hand, the ASI algorithm, which can offer higher-resolution
SIC estimates, was assessed by Wiebe and others (2009) using the same validation data as Cavalieri and others (2006). Averaged over all ice types, the bias ranged between $2.0 \%$ and $17.4 \%$, and new ice had a lower accuracy than first-year and young ice. For the more complex Antarctic winter sea ice, Cavalieri and others (2010) compared AMSR-E NT2 products with ten Moderate Resolution Imaging Spectroradiometer (MODIS) images and observed that the averaged SIC biases relative to MODIS ranged from $<-0.5 \%$ to $-18 \%$, and the RMSE ranged from $2 \%$ to $24 \%$. These values were much higher than in the Arctic. Furthermore, the bias and RMSE were correlated with the fractions of new ice and open water, indicating that the largest errors occurred in the marginal ice zone and along the ice edge. Other previous research also pointed to a relatively low agreement in the marginal edge zone, especially during the ice melt season (e.g. Worby and Comiso, 2004; Ozsoy-Cicek and others, 2009, 2011; Wiebe and others, 2009). This study mainly focused on areas with potentially lower accuracy; therefore, the focus was on the assessment of the sea-ice edge in the Antarctic during summer.

An ice concentration threshold of $15 \%$ is commonly used when determining the sea-ice edge from passive microwave ice concentration products. Worby and Comiso (2004) questioned the reliability of sea-ice edge derived from $15 \%$ SIC. After comparing edge locations observed by Special Sensor Microwave/Imager (SSM/I), ships and a variety of optical and SAR images, they found that $1-2^{\circ}$ latitude $(>100 \mathrm{~km})$ offsets occurred in the summer ice-edge locations. Heinrichs and others (2006) assessed the AMSR-E ice concentration product at the ice edge and arrived at the more inspiring conclusion that the position of the ice edge determined by $15 \%$ SIC was on average within one AMSR-E grid square $(12.5 \mathrm{~km})$ of the ice edge determined from SAR 
data. Similarly, Ozsoy-Cicek and others (2009) validated the AMSR-E NT2 product using ship observations from the Oden expedition during an Antarctic summer. They determined that the AMSR-E-derived ice edge was further south and that there was a poor correlation between ship observations and the AMSR-E SIC. All the ship observations mentioned above were recorded using a standard protocol from the Antarctic Sea Ice Processes and Climate (ASPeCt) program within the Scientific Committee on Antarctic Research (Worby and Allison 1999).

Although ship observation records obtained from Antarctic expeditions have been used to map the sea-ice edge and have been compared with satellite-derived data, the number of ship observations that are located exactly at the sea-ice edge is very limited. For example, there are 36 iceedge data points presented in Worby and Comiso (2004); of a total of 384 ship observations during two ship cruises, 58 were in the marginal zone (Ozsoy-Cicek and others, 2011). However, to assess the ice-edge accuracy by performing reliable statistical analysis, a sufficient number of observations at the ice edge are required. In this context, we propose a new method to generate pseudo-ship observations from optical satellite images, in accordance with the ASPeCt standard ship-based observation protocol. The number of ice-edge data points was expected to be greatly expanded with this method. Furthermore, the spatial coverage of the pseudo-ship observations would be wider and more flexible than in situ observations, which are constrained by the cruise route.

\section{METHODOLOGY}

This study used data from an AMSR-E ASI dataset and a MODIS dataset. The MODIS data were classified to sea-ice binary maps, and pseudo-ship observations were then generated based on ASPeCt. The datasets are described and the method of processing is explained below.

\section{Dataset I: AMSR-E ASI ice concentration (SIC $\mathrm{CSI}_{\text {AS }}$ )}

The AMSR-E sensor was operating aboard the NASA Aqua platform between 2002 and 2011. It provides data on both horizontally and vertically polarized brightness temperatures at six different frequencies between 6.9 and $89.0 \mathrm{GHz}$. Standard AMSR-E daily sea-ice concentrations are derived using the NASA NT2 algorithm (Markus and Cavalieri, 2000), with spatial resolutions of 12.5 and $25.0 \mathrm{~km}$. The ASI algorithm (Kaleschke and others, 2001; Spreen and others, 2008) was developed as a way to obtain more detail from the high spatial resolution of the $89 \mathrm{GHz}$ channels and shows a performance similar to other sea-ice algorithms (Spreen and others, 2008). In this study, we selected an ASI ice concentration grid at a $6.25 \mathrm{~km}$ spatial resolution to capture the edge location. Because the ASI is applied to daily average products and not to daily ascending or descending images, a publicly distributed ASI daily average grid was chosen to enable users of the products to benefit from a better understanding of their qualities.

Daily average $\mathrm{ASI}$ grids $\left(\mathrm{SIC}_{\mathrm{ASI}}\right)$ with a $6.25 \mathrm{~km}$ resolution were obtained using the current version of the ASI algorithm, which is described in detail by Spreen and others (2008). All the data were produced by the Institute of Environmental Physics (IUP) at the University of Bremen, Germany, and were downloaded from http://iup.physik.uni-bremen.de: 8084/amsredata/asi_daygrid_swath/l1a/s6250/. The SIC ASI were in a GeoTIFF format, which is available as bytes (0-255) and with a polar stereographic projection. The ice concentrations between $0 \%$ and $100 \%$ were scaled to values between 0 and 200, so that every value of the GeoTIFF byte data represents a $0.5 \%$ ice concentration range.

\section{Dataset II: MODIS}

The MODIS image was chosen to serve as the primary independent evaluation source. MODIS has 36 visible/ infrared bands with spatial resolution ranging from $250 \mathrm{~m}$ to $1 \mathrm{~km}$. Four MODIS images were obtained for the dates when the synchronous Landsat TM images also had atmospherically clear conditions. Although MODIS has a coarser resolution than $\mathrm{TM}$, it covers a much wider swath, thereby permitting greater coverage of both AMSR-E pixels and ice edges. Landsat TM images were used in this study as a secondary referencing source for explaining our results.

The four MODIS scenes that were used in this study cover portions of the Weddell Sea, Pacific Ocean and Bellingshausen Sea (Fig. 1). The MOD 02-Level-1B Calibrated Geolocation Data Set were downloaded from the Atmosphere Archive and Distribution System (http://ladsweb.nascom.nasa.gov). Using a MODIS geolocation product, a sunangle correction was applied to the reflectance of band 1 $(0.620-0.670 \mathrm{~m})$ and band $2(0.841-0.876 \mathrm{~m})$ at a $250 \mathrm{~m}$ resolution and to band $4(0.545-0.565 \mathrm{~m})$ and band 6 $(1.628-1.652 \mathrm{~m})$ at a $500 \mathrm{~m}$ resolution, to generate top-ofthe-atmosphere reflectance. Next the top-of-the-atmosphere reflectances for each band in swath form were transformed into a polar stereographic projection.

\section{Data processing I: sea-ice binary map and pseudo- ASPeCt observations}

A multiple thresholds method was employed following NASA's MODIS sea-ice product processing approach (Riggs and others, 2006). This approach defines ice and no-ice thresholds using multiple bands, by allowing each MODIS pixel to be classified either as ice or not ice. First we regridded bands 4 and 6 to a $250 \mathrm{~m}$ resolution and calculated the normalized-difference snow index (NDSI) using NDSI $=\left(\operatorname{Ref}_{\text {band } 4}-\operatorname{Ref}_{\text {band } 6}\right) /\left(\operatorname{Ref}_{\text {band } 4}+\operatorname{Ref}_{\text {band } 6}\right)$, where $\operatorname{Ref}_{\text {band4 }}$ and $\operatorname{Ref}_{\text {band6 }}$ indicate the reflectance of bands 4 and 6 , respectively. Next if a MODIS pixel fulfilled the three criteria NDSI $>0.4, \operatorname{Ref}_{\text {band1 } 1}>0.1$ and $\operatorname{Ref}_{\text {band2 }}>$ 0.11 , it was labeled as ice, otherwise it was labeled as no ice. Using this method, the MODIS images were classified into binary sea-ice maps with values of 1 (ice) and 0 (no ice) at a $250 \mathrm{~m}$ resolution. This binary map was used to generate pseudo-ship points in the next step.

The sea-ice edge was defined as the northernmost occurrence of sea ice with at least a $10 \%$ concentration, where the ice concentration within a $1 \mathrm{~km}$ radius of the ship is estimated from the ship's bridge (Worby and Comiso, 2004). To simulate the ice-edge determination it was necessary to 'look at' an ice concentration map from space with a $1 \mathrm{~km}$ radius, instead of from a ship, and to identify the northernmost $10 \%$ concentration point. In this study we replaced the $1 \mathrm{~km}$ radius with a $2 \mathrm{~km}$ resolution grid, which was derived from the binary ice map by averaging the values of every $8 \times 8$ cell grid. Next, we established the contours of a $10 \%$ SIC from the $2 \mathrm{~km}$ ice concentration grid and marked the ASI pixels passing the contours as pseudo-ship-observed pixels. In total, 917 pseudo-ASPeCt observations were sampled from four scenes (Table 1). 


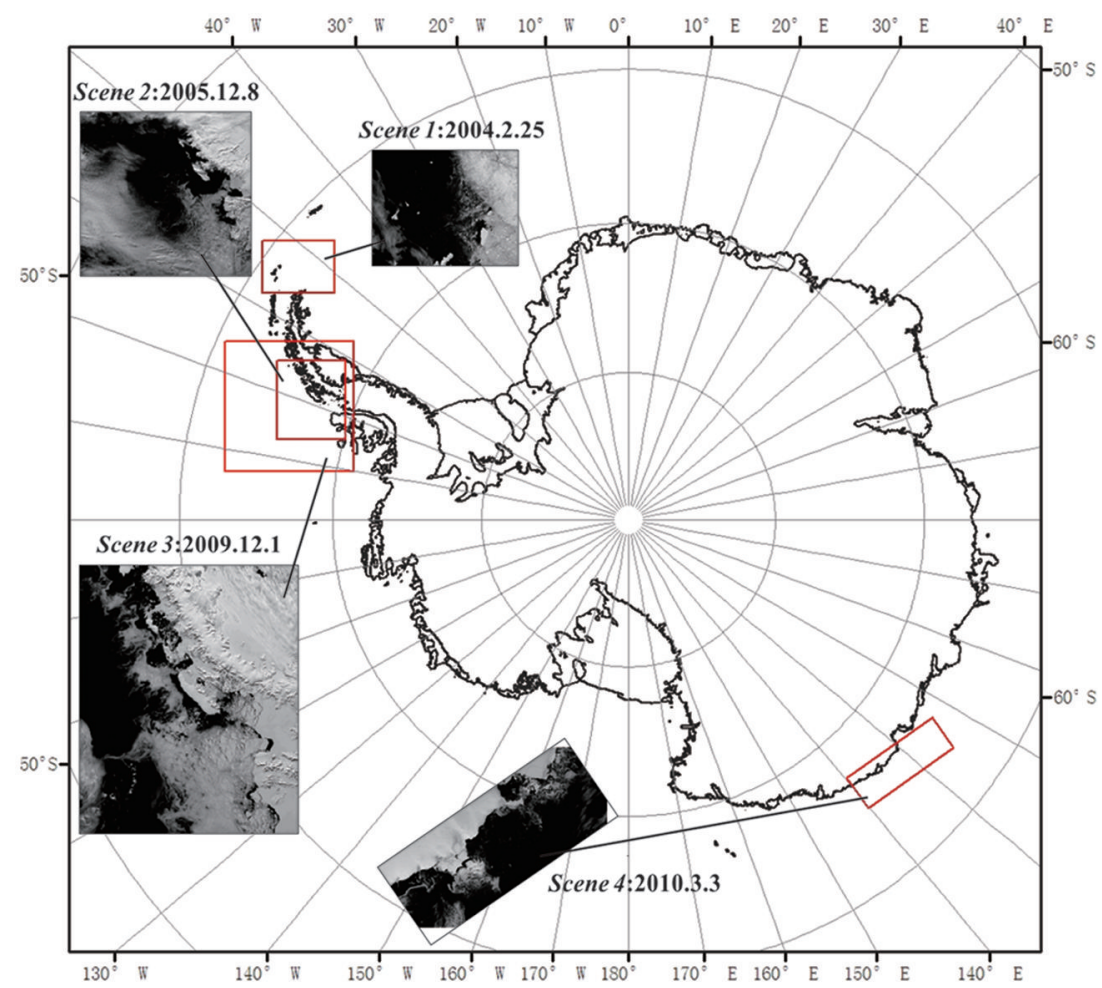

Fig. 1. Location of the four MODIS scenes in the Antarctic. Date format is year.month.day.

\section{Data processing II: comparison of ice edges and transects}

Ideally, we might expect that all 917 ASI pixels covering pseudo-ASPeCt observations have the same SIC value of $15 \%$; if so, the $15 \%$ threshold for passive microwave images would be pertinent. To be more flexible, we hypothesized that the mean concentration should not be significantly different from 15\%. Furthermore, the 917 ASI pixels should have concentration values $\left(\mathrm{SIC}_{\mathrm{ASI}}\right)$ similar to their corresponding MODIS pixels ( $\mathrm{SIC}_{\text {MODIS }}$ ). $\mathrm{SIC}_{\text {MODIS }}$ is calculated as the average value of the $25 \times 25$ cells on a binary ice map that match the size of the corresponding $6.25 \mathrm{~km}$ ASI pixel. Descriptive statistics and a correlation analysis were performed to compare $\mathrm{SIC}_{\mathrm{ASI}}$ and $\mathrm{SIC}_{\text {MODIS }}$ data. In addition to the ice concentrations, the spatial variability of the ice edges was also considered. The outlines of the cell regions with a $10 \%$ concentration on the $2 \mathrm{~km}$ resolution grid were marked as the pseudo-ice edge. The distance between the location of the pseudo-ice edge and the $15 \% \mathrm{SIC}_{\mathrm{ASI}}$ contour was analyzed.

To assess the accuracy of $\mathrm{SIC}_{\mathrm{ASI}}$ at the ice edge with that in open water and in the interior zone, we drew eight transects (i.e. two on each scene). All the transects started at the ice interior, passed the ice edge and marginal zone, and reached the open water. The $\mathrm{SIC}_{\mathrm{ASI}}$ and $\mathrm{SIC}_{\mathrm{MODIS}}$ data along these transects were compared. The pseudo-ASPeCt observations on the transects were marked out to be compared with the $15 \%$ SIC.

\section{RESULTS \\ Comparison of ASI ice concentration $\left(\mathrm{SIC}_{\mathrm{ASI}}\right)$ and pseudo-ASPeCt observations}

The summary statistics of $\mathrm{SIC}_{\mathrm{ASI}}$ at the pseudo-ASPeCt points for each scene are shown in Table 1. The mean and standard deviation of $\mathrm{SIC}_{\mathrm{ASI}}$ ranged from $0.8 \%$ to $19.9 \%$ and $2.9 \%$ to

Table 1. Details of the four MODIS scenes and a comparison of $\mathrm{SIC}_{\mathrm{ASI}}$ and $\mathrm{SIC}_{\mathrm{MODIS}}$ from pseudo-ASPeCt observations

\begin{tabular}{|c|c|c|c|c|c|c|c|c|}
\hline & \multirow[t]{3}{*}{ Date } & \multirow[t]{3}{*}{ Number of edge points } & \multicolumn{2}{|c|}{$\mathrm{SIC}_{\mathrm{ASI}}$} & \multirow{3}{*}{$\begin{array}{l}Z \text { test for difference } \\
\text { with } 15 \%\end{array}$} & \multicolumn{3}{|c|}{$\mathrm{SIC}_{\mathrm{ASI}}-\mathrm{SIC}_{\mathrm{MODIS}}$} \\
\hline & & & Mean & Std dev. & & Bias & RMS & $R^{2}$ \\
\hline & & & $\%$ & $\%$ & & $\%$ & $\%$ & \\
\hline Scene 1 & 25 Feb 2004 & 98 & 0.8 & 2.9 & $-48.376^{*}$ & -15.1 & 19.2 & $0.2^{*}$ \\
\hline Scene 2 & 8 Dec 2005 & 364 & 10.6 & 21.4 & $-3.051^{*}$ & -12.3 & 30.5 & $0.03 *$ \\
\hline Scene 3 & 1 Dec 2009 & 182 & 12 & 17.9 & $-2.301^{*}$ & -12.8 & 28 & $0.1^{*}$ \\
\hline Scene 4 & 3 Mar 2010 & 273 & 19.9 & 24.1 & $13.648^{*}$ & 0.5 & 26.2 & $0.05^{*}$ \\
\hline Total & & 917 & 13 & 21.2 & $-2.903 *$ & -8.9 & 27.7 & $0.04^{*}$ \\
\hline
\end{tabular}

*Statistically significant at a 0.05 level. 

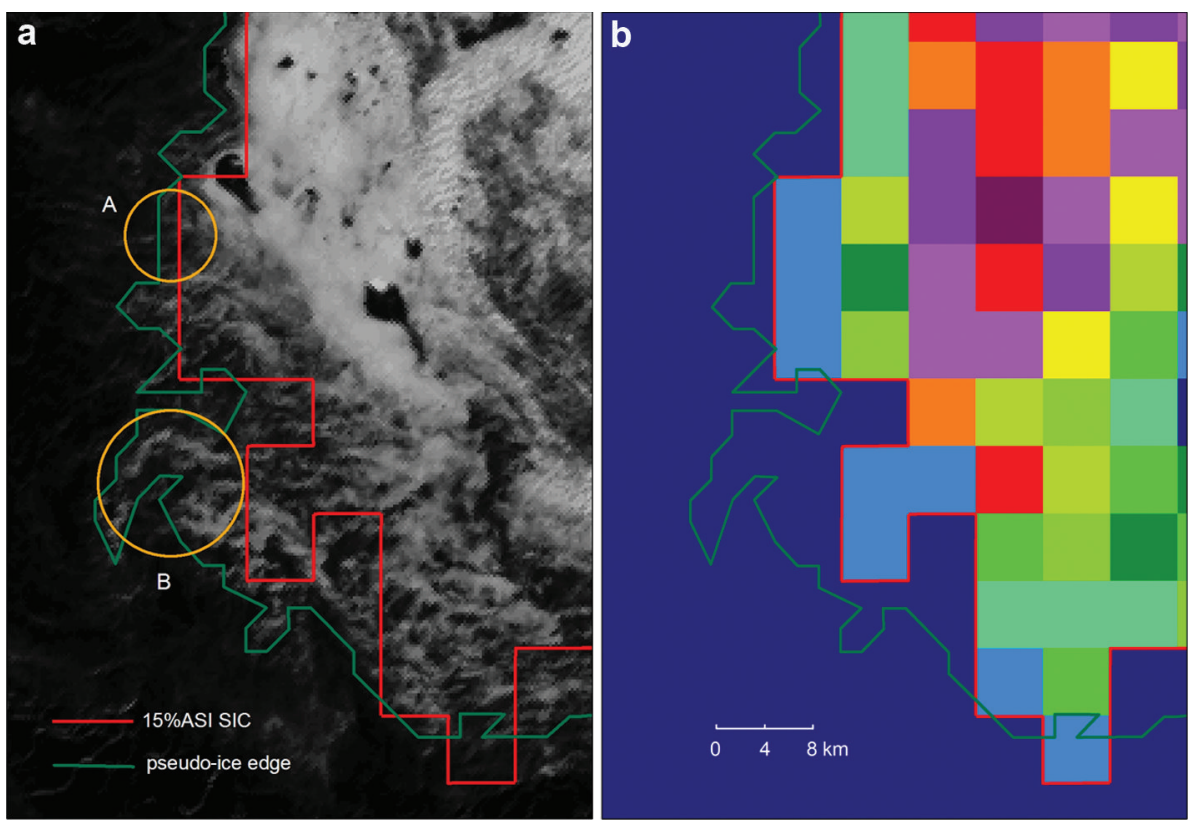

Fig. 2. Contour of the $15 \%$ ASI SIC threshold and the pseudo-ice edge overlaid on the original MODIS band 2 (a) and the ASI concentration product (b). This region is the subset of scene 2. Yellow circles highlight regions A and B where representative types of gaps occur.

$24.1 \%$, respectively. Scenes 2,3 and 4 had similar mean ice concentrations of $\sim 15 \%$ and standard deviations of $\sim 20 \%$. The closest concentration to the $15 \%$ standard threshold was $12 \%$, derived from scene 3 . Of the four scenes, scene 1 is the exception, with a lower mean concentration and smaller standard deviation than the others. Putting all the sample points together, we observed that the mean $\mathrm{SIC}_{\mathrm{ASI}}$ value was $13 \%$. Means testing ( $Z$ tests) indicated that all the mean values were significantly different from $15 \%$ at a 0.05 significance level, although a $2 \%$ difference seems remarkably good. The reason could be the large number of sample points. Therefore, the difference between the mean and 15\% was so large that we know with 95\% certainty the difference was not by chance.

Although the differences between the ice concentration values were significant, the spatial separation of the edges could be small. For example, the ice edges derived from the $\mathrm{ASI}$ and ASPeCt observations have a small distance within one or half a pixel size, but their concentration values can be significantly different. Consequently, we checked the spatial locations of the $15 \%$ ASI threshold and pseudo-ice edges, and overlaid these on the original MODIS image and the ASI product (similar to Fig. 2). Generally, the 15\% ASI contour was located south of the pseudo-ice edge. We found that the average distance between the two lines did not exceed three ASI pixels, whereas $58 \%$ of the separation space is approximately one pixel in width. Some small gaps within one pixel or half a pixel were due to the coarse resolution of the AMSR-E image (region A in Fig. 2). Large distances, such as region B in Figure 2, primarily occurred in thin-ice areas with low sea-ice concentration.

\section{Comparison of ASI and MODIS ice concentration $\left(S_{I C} C_{A S I}-S_{\text {MODIS }}\right)$ at the pseudo-ASPeCt observation points}

The correlation of $\mathrm{SIC}_{\mathrm{ASI}}$ vs $\mathrm{SIC}_{\text {MODIS }}$ ice concentrations at pseudo-ASPeCt points in each scene is illustrated by the scatter plots in Figure 3. Because all the $\mathrm{SIC}_{\mathrm{ASI}}$ and $\mathrm{SIC}_{\mathrm{MODIS}}$ values were collected at sea-ice edges, the points were clustered near the bottom left-hand corner of the plots with low ice concentrations. Many dots have a zero SIC ASI $_{\text {but a }}$ non-zero $\mathrm{SIC}_{\text {MODIS }}$ value, thereby aligning on the left-hand side border of the scatter plot. A large number of these dots will reduce the strength of the correlations, as confirmed by their low $R^{2}$ values $\left(R^{2} \leq 0.2\right)$. The test results, however, showed that the correlation coefficients were significantly different from zero, indicating low but significant linear relationships (Table 1 ).

The bias $\left(\mathrm{SIC}_{\mathrm{ASI}}-\mathrm{SIC}_{\mathrm{MODIS}}\right)$ and RMSE values for each scene are summarized in Table 1. Three of the four scenes had a negative bias, ranging from $-15.1 \%$ to $-12.3 \%$, whereas the fourth scene had a bias close to zero. The average bias for all the sample points was negative, indicating a general underestimation by the AMSR-E ASI products at the sea-ice edges. All the RMSE values were between 19\% and $31 \%$, with an average of $27.7 \%$. These values were compared with previous studies, as discussed below.

\section{Comparison of ASI and MODIS ice concentrations $\left(\mathrm{SIC}_{\mathrm{ASI}}-\mathrm{SIC}_{\text {MODIS}}\right)$ along transects}

To illustrate the concentration differences in the ice cover along the ice edge, eight transects across the pseudo-ASPeCt observation points were derived from the four scenes (Fig. 4). The order of the starting point, end point and pseudo-ASPeCt point was labeled. All the transects start from the ice interior, pass the ice edges of the pseudoASPeCt points and reach $100 \%$ open water. Some transects had relatively sharp and compact ice edges (e.g. 2005a), others had more uncertain and gradual edges (e.g. 2009b), and others had obvious low-concentration segments in the interior ice region (e.g. 2004b and 2005b). The $R^{2}$ values of a regression between SIC $_{\text {ASI }}$ VS SIC MODIS along the transects ranged between 0.69 and 0.96 and were therefore much higher than the values observed at the pseudo-ASPeCt points along the ice edge. Clearly, strong agreement exists between $\mathrm{SIC}_{\mathrm{ASI}}$ and $\mathrm{SIC}_{\mathrm{MODIS}}$ in the inner dense ice zones and in the open sea areas, whereas the differences in the transition zones were larger, with generally higher $\mathrm{SIC}_{\text {MODIs }}$ values 

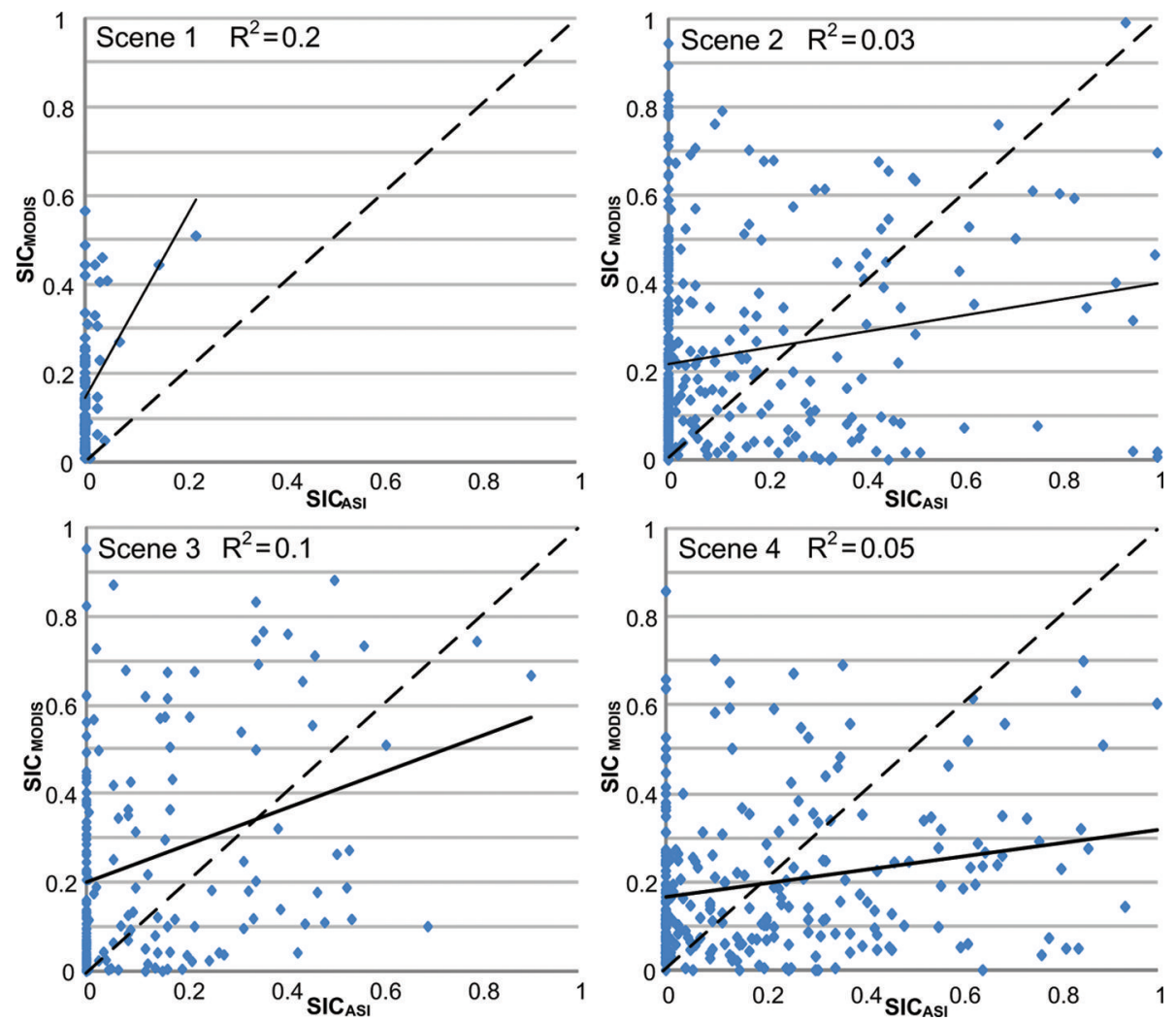

Fig. 3. Sea-ice concentrations from $\mathrm{SIC}_{\mathrm{ASI}} \mathrm{vs} \mathrm{SIC}_{\mathrm{MODIS}}$ at pseudo-ASPeCt observation points in four scenes. The solid black line represents the best linear fit of the data and the dashed line represents a $1: 1$ relationship.
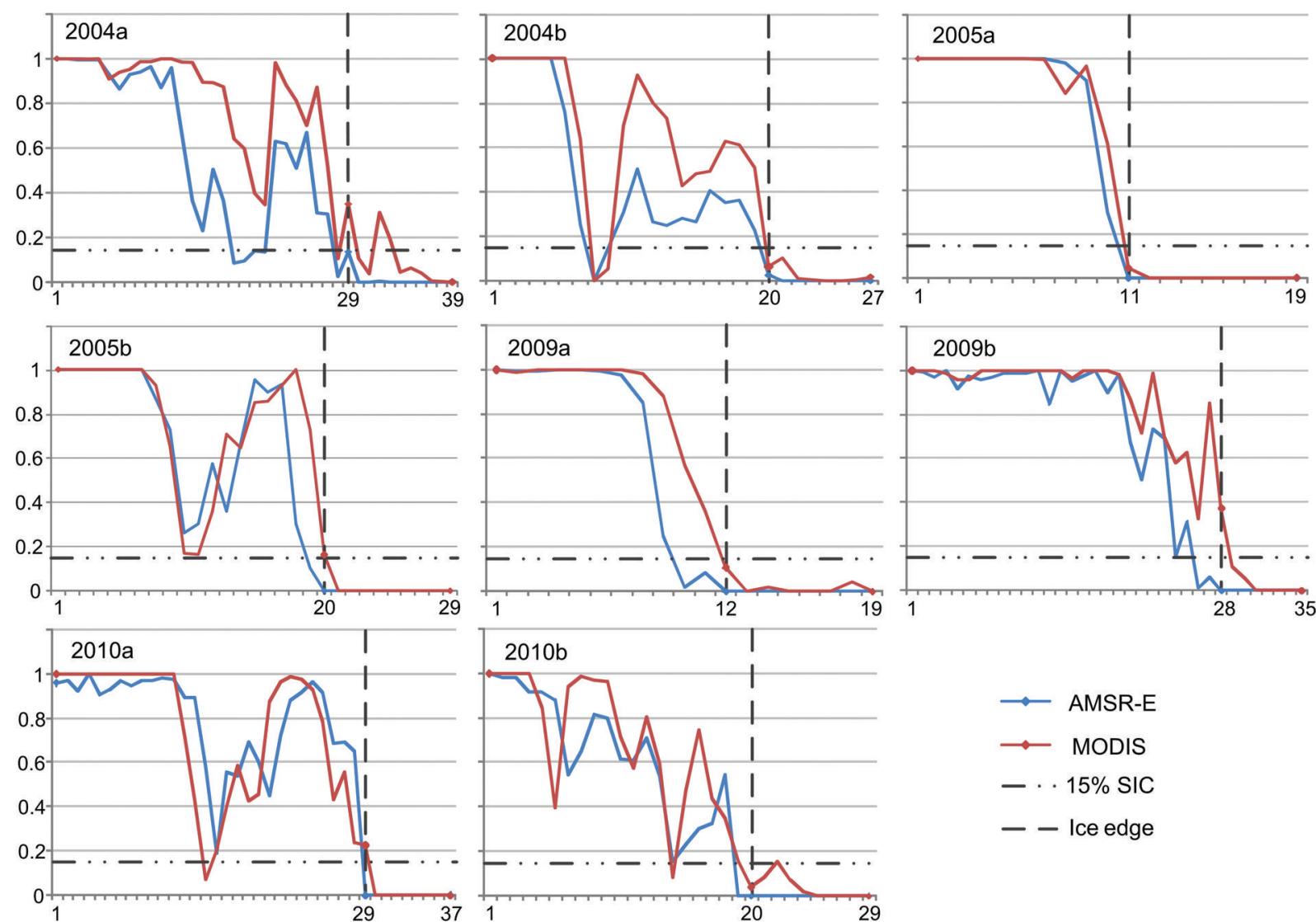

Fig. 4. Sea-ice concentrations from $\mathrm{SIC}_{\mathrm{ASI}}$ vS $\mathrm{SIC}_{\mathrm{MODIS}}$ along eight transects. The $x$-axis units are pixels. The vertical dashed lines represent the location of the pseudo-ASPeCt observation points, and the horizontal dotted and dashed lines show the $15 \%$ passive microwave concentration. 


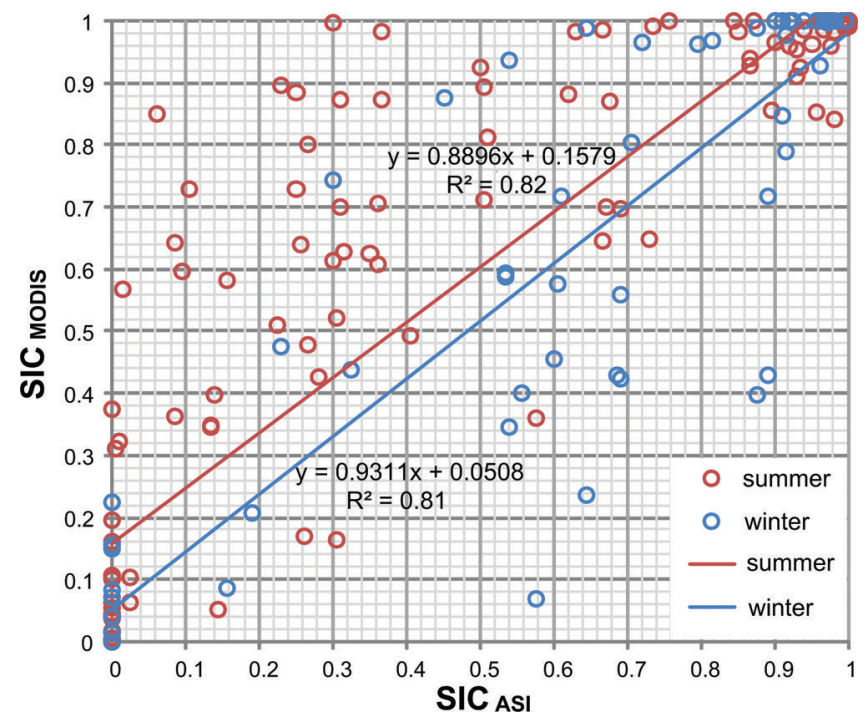

Fig. 5. Scatter plot of $\mathrm{SIC}_{\mathrm{ASI}} \mathrm{vS} \mathrm{SIC}_{\mathrm{MODIS}}$ from all ASI pixels in eight transects.

This underestimation of $\mathrm{SIC}_{\mathrm{ASI}}$ in the marginal zone is consistent with our results (Fig. 3).

The vertical dashed lines in Figure 4 represent the locations of the ice edge as observed from the pseudoASPeCt points, and the horizontal dotted and dashed lines represent the $15 \%$ ice concentration threshold. At the locations of the ice edge, only the SIC $_{\text {ASI }}$ in 2004a achieved a $15 \%$ threshold, whereas all the others were below $15 \%$. However, the comparisons in Table 1 show a higher mean $\mathrm{SIC}_{\mathrm{ASI}}$ over $15 \%$ in scene 4 in 2010 . This inconsistency suggests that the small number of ship-based observations at the ice edge cannot accurately represent the overall ice-edge line. Combining the transect analysis with robust statistics based on a large number of points generated from our proposed method provides a full understanding of the data quality. The distance between a pseudo-ASPeCt point and the northernmost $\mathrm{SIC}_{\mathrm{ASI}}$ pixel with at least a $15 \%$ SIC were all between zero and three pixels wide, with an average of 1.625 pixels $(\sim 10 \mathrm{~km})$. These values are in good agreement with our observations (Fig. 2).

Separating the data into summer (scenes 1,2 and 3) and winter (scene 4) highlights the underestimation of $\mathrm{SIC}_{\mathrm{ASI}}$ in summer: many more red points lie above the diagonal than below it (Fig. 5). In contrast, the blue points are distributed more evenly around the diagonal and do not have a large bias. The overall $R^{2}$ values were 0.82 and 0.81 in summer and winter, respectively. Figure 5 also revealed that the majority of points were clustered in the top right-hand and bottom left-hand corners, i.e. located in the ice interior and in $100 \%$ open water, respectively. Only a small portion of the points had moderate ice concentrations and most were scattered far from the regression lines. This suggests that the high correlation coefficient values were mainly attributable to the major corner points, and the small number of ice edge points prohibited further conclusions being drawn from this transect analysis.

\section{DISCUSSIONS}

The objective of this study was the localization of sea-ice edges and their corresponding ASI concentration. Previous research (e.g. Worby and Comiso 2004; Ozsoy-Cicek and others, 2011) also compared the 15\% threshold from passive microwave images with the ice edges observed from higher-resolution images or from ships, but there was no standard definition of the ice edge when it was extracted from higher-resolution images. Difficulties also occurred when the ship records were sparse at the exact ice-edge locations. Using the ASPeCt ice-edge definition, we retrieved ice concentrations from a MODIS image and determined the ice-edge points using a $2 \mathrm{~km}$ resolution in accordance with ASPeCt. This method takes advantage of using easily acquired (MODIS) imagery to generate a large number of pseudo-ASPeCt observations for each scene, and hence contributes to a robust statistical analysis of ice-edge accuracy.

Statistical analysis indicated that the ASPeCt observations, for all scenes and on average, have significantly different mean concentrations from the $15 \%$ concentration, although some were close to this value. The correlation between $\mathrm{SIC}_{\mathrm{ASI}}$ and $\mathrm{SIC}_{\text {MODIs }}$ values at the ice edge was low $\left(R^{2} \leq 0.2\right)$, but all the linear relationships were statistically significant. These correlation coefficients were lower than those reported in previous studies (e.g. Ozsoy-Cicek and others, 2011). This may have resulted from the different ice concentration retrieval methods (ASI vs NT2). However, it is more likely due to the fact that our research relied on a much larger number of samples, which were located exactly at the ice edge instead of within the marginal ice zone. Therefore, simulated pseudo-ship observations and quantitative comparisons in this study helped us to gain a better understanding of the performance of AMSR-E concentration products along the ice edge.

In spite of the significantly different concentration values, the distances between the generated ice edges and the 15\% threshold were within three AMSR-E pixels and an average of $\sim 10 \mathrm{~km}$. Many large gaps occur in areas with thin ice and low ice concentrations, which can be explained by the following three phenomena:

1. As thin ice often appears dark with near-freezing temperatures, there is the potential for significant uncertainty when discriminating thin ice from surrounding open water using visible and infrared MODIS image bands (Riggs and others, 2006).

2. When using the $6.25 \mathrm{~km}$ resolution channels and output concentration of $6.25 \mathrm{~km}$, the ASI algorithm uses lowerfrequency channels with lower spatial resolution for weather filtering, which removes spurious ice concentrations in open water at ice edges (Spreen and others, 2008). The resolution of these weather-filtering channels is $\sim 15-20 \mathrm{~km}$, which is approximately three gridcells.

3. Some of the difference may be a result of a temporal sampling issue. The AMSR-E data are a daily average, whereas the MODIS data are a snapshot. It is possible that the difference in sampling time may reach 24 hours. A substantial amount of sea ice can grow within 24 hours, depending on the conditions. For example, ice missed by the ASI (Fig. 2) may be newly formed ice.

Generally, the $10 \mathrm{~km}$ separation is within an acceptable range of accuracy compared with other passive microwave ice concentration products, which have coarser spatial resolutions (e.g. 12.5 and $25.0 \mathrm{~km}$ ). This finding is similar to a previous conclusion that an average distance of 
$\sim 12 \mathrm{~km}$ exists between the $15 \%$ threshold and the SARderived edges (Heinrichs and others, 2006). A comparison between the generated pseudo-ice edges and the US National Ice Center (NIC) sea-ice chart should be addressed in a future study.

Our comparison of AMSR-E ASI and MODIS data indicated that the AMSR-E ASI products tend to underestimate the ice concentrations at the ice edges, especially during the Antarctic summer. Another ice concentration algorithm, NT2, applied to AMSR-E images obtained similar results. For example, Heinrichs and others (2006) and Ozsoy-Cicek and others (2009) noted that the AMSR-E NT2 products tended to underestimate low ice concentrations in areas with thin ice, both during the Antarctic summer and the Arctic spring. More specifically, some studies further classified the thin-ice area as new ice, young ice and first-year ice (Cavalieri and others, 2006, 2010), and discovered that a higher fraction of new ice and open water could lead to a larger negative bias of AMSR-E NT2 relative to MODIS or Landsat. Wiebe and others (2009) examined AMSR-E ASI products from Landsat-7 ETM+ and SAR images during the Arctic spring. They reported little underestimation of ASI products for both young ice and first-year ice and larger errors for new ice. For the Antarctic, our results gave a slightly larger negative bias and larger RMSE values at the ice edge derived from an ASI algorithm. In the future, the ice type classification can be applied to our collected Landsat Thematic Mapper (TM) images for detailed error assessment.

The daily average ice concentration product was chosen for this research because it is distributed publicly and is used widely. Therefore, users of the products can benefit from our quality assessment. To track ice-edge movement more precisely, the daytime (ascending pass) and night-time (descending pass) AMSR-E images should be selected to minimize their temporal differences from the reference images. Only four images were included here, but more scenes are needed for future study, especially covering the East Antarctic region. However, the proposed method for generating a large number of ice-edge ASPeCt observations can be applied to the assessment of other passive microwave images and to other ice concentration algorithms.

\section{CONCLUSIONS}

This study generated pseudo-ship observations from MODIS images based on the definition of ice-edge points from the ASPeCt protocol. We used these observations to evaluate sea-ice concentrations of AMSR-E ASI at the ice edge. In total, 917 points were sampled from the three MODIS scenes during the Antarctic summer and from one scene in winter. Our statistical tests indicated that the ASI pixels passing pseudo-ASPeCt observations had a mean value of $13 \%$ and were significantly different from the $15 \%$ threshold. The spatial separation between the pseudo-ice edges and the contour of the $15 \%$ threshold was within three $6.25 \mathrm{~km}$ pixels and $\sim 10 \mathrm{~km}$ on average. Comparing this with the ice concentrations derived from MODIS, we found that the ASI products tended to underestimate the concentration at the ice edge, especially during the summer. Their correlations were surprisingly poor, with $R^{2}$ values $<0.2$. This was due to the large number of zero ASI pixels that could not detect thin ice with low concentrations at the ice edge. From a transect analysis that covered the ice interior, marginal ice zone and open water, we obtained correlation coefficients $>0.8$. Large differences in ice concentrations existed in the marginal ice zone and ice edge, whereas small differences occurred in the interior and water areas. Underestimation of $\mathrm{SIC}_{\mathrm{ASI}}$ occurred across the region in the summer and no apparent bias occurred during the winter. This newly developed method provides a way of generating a new source of reference data, in which the spatial coverage is wider and more flexible than for traditional in situ observations. It can also be used in other places, to assess ice concentration products using rigorous statistical analysis.

\section{ACKNOWLEDGEMENTS}

This work was partially supported by the National Natural Science Foundation of China (grant No. 41301463), Specialized Research Fund for the Doctoral Program of Higher Education (grant No. 20130141120009) and the Fund of Key Laboratory of Global Change and Marine-Atmospheric Chemistry, SOA (GCMAC1305). We thank the Institute of Environmental Physics (IUP), University of Bremen, Germany, for providing ASI concentration data, and NASA Goddard Space Flight Center (GSFC) for providing the MODIS dataset. We also thank two anonymous referees, Hiroyuki Enomoto and Petra Heil for the review and editorial comments, which improved the manuscript.

\section{REFERENCES}

Cavalieri DJ, Markus T, Hall DK, Gasiewski AJ, Klein M and Ivanoff A (2006) Assessment of EOS Aqua AMSR-E Arctic sea ice concentrations using Landsat-7 and airborne microwave imagery. IEEE Trans. Geosci. Remote Sens., 44(11), 3057-3069 (doi: 10.1109/TGRS.2006.878445)

Cavalieri DJ, Markus T, Hall DK, Ivanoff A and Glick E (2010) Assessment of AMSR-E Antarctic winter sea-ice concentrations using Aqua MODIS. IEEE Trans. Geosci. Remote Sens., 48(9), 3331-3339 (doi: 10.1109/TGRS.2010.2046495)

Heinrichs JF, Cavalieri DJ and Markus T (2006) Assessment of the AMSR-E sea-ice concentration product at the ice edge using RADARSAT-1 and MODIS imagery. IEEE Trans. Geosci. Remote Sens., 44(11), 3070-3080 (doi: 10.1109/TGRS.2006.880622)

Kaleschke $\mathrm{L}$ and 6 others (2001) SSM/I sea ice remote sensing for mesoscale ocean-atmosphere interaction analysis. Can. J. Remote Sens., 27(5), 526-537

Lee $\mathrm{H}$ and Han $\mathrm{H}$ (2008) Evaluation of SSM/I and AMSR-E sea ice concentrations in the Antarctic spring using KOMPSAT-1 EOC images. IEEE Trans. Geosci. Remote Sens., 46(7), 1905-1912 (doi: 10.1109/TGRS.2008.916479)

Markus T and Cavalieri DJ (2000) An enhancement of the NASA Team sea ice algorithm. IEEE Trans. Geosci. Remote Sens., 38(3), 1387-1398 (doi: 10.1109/36.843033)

Massom RA and Stammerjohn SE (2010) Antarctic sea ice change and variability - physical and ecological implications. Polar Sci., 4(2), 149-186 (doi: 10.1016/j.polar.2010.05.001)

Ozsoy-Cicek B, Xie H, Ackley SF and Ye K (2009) Antarctic summer sea ice concentration and extent: comparison of ODEN 2006 ship observations, satellite passive microwave and NIC sea ice charts. Cryosphere, 3(1), 1-9 (doi: 10.5194/tc-3-1-2009)

Ozsoy-Cicek B, Ackley SF, Worby A, Xie H and Lieser J (2011) Antarctic sea ice extents and concentrations: comparison of satellite and ship measurements from International Polar Year cruises. Ann. Glaciol., 52(57 Pt 2), 318-326 (doi: 10.3189/ $172756411795931877)$ 
Parkinson CL and Cavalieri DJ (2012) Antarctic sea ice variability and trends, 1979-2010. Cryosphere, 6(4), 871-880 (doi: 10.5194/tc-6-871-2012)

Riggs GA, Hall DK and Salomonson VV (2006) MODIS Sea Ice Products user guide to Collection 5. NASA Goddard Space Flight Center, Greenbelt, MD. http://modis-snow-ice.gsfc. nasa.gov

Spreen G, Kaleschke L and Heygster G (2008) Sea ice remote sensing using AMSR-E 89-GHz channels. J. Geophys. Res., 113(C2), C02S03 (doi: 10.1029/2005JC003384)
Wiebe H, Heygster G and Markus T (2009) Comparison of the ASI ice concentration algorithm with Landsat-7 ETM+ and SAR imagery. IEEE Trans. Geosci. Remote Sens., 47(9), 3008-3015 (doi: 10.1109/TGRS.2009.2026367)

Worby AP and Allison I (1999) A technique for making ship-based observations of Antarctic sea ice thickness and characteristics. Part I: Observational techniques and results. Antarct. CRC Res. Rep. 14 Worby AP and Comiso JC (2004) Studies of the Antarctic sea ice edge and ice extent from satellite and ship observations. Remote Sens. Environ., 92(1), 98-111 (doi: 10.1016/j.rse.2004.05.007) 